\title{
A Successful Pregnancy Outcome In A Bicornuate Bicollis Uterus
}

\author{
Dr. Channareddy Sunitha ${ }^{1}$, Assistant Professor, Dr. Sajana Gogineni ${ }^{2}$, Professor \\ Dr. Sravanthi Madivada ${ }^{3}, \mathrm{PG}$ \\ 1,2,3 (Dept. of OBG, Dr. PSIMS \& RF, Chinoutpalli, AP, India)
}

\begin{abstract}
The incidence of congenital uterine malformation is estimated to be 3-5\% in general population. Abnormal fusion of Mullerian duct in embryonic life results in variety of malformations. Here, we report a case of successful pregnancy outcome in a Bicornuate bicollis uterus with communicating cavities that was initially diagnosed by USG. Clinically we found double cervix and by USG two horns. PPROM with non reassuring foetal heart rate later in pregnancy necessitated an emergency LSCS at 34Wks of gestation. The diagnosis was confirmed intra operatively by exteriorizing the uterus and noting the communicating cavities.
\end{abstract}

Key words- Bicornuate bicollis, Communicating cavities, Mullerian anomaly, Asymmetric IUGR.

\section{Introduction}

Incomplete fusion of the Mullerian or paramesonephric ducts results in the most common types of uterine malformation: uterus didelphys, uterus bicornis bicollis, uterus bicornis unicollis, uterus subseptae, uterus arcuatus, uterus unicornis. Uterus bicornis bicollis ${ }^{1}$ is characterized by double or single vagina, double cervix and two single-horned uteruses which show partial fusing of their muscular walls with duplication running right down to the uterine orifice. These malformations are rare but known to be associated with infertility, spontaneous miscarriages, intrauterine growth restriction, preterm deliveries, preterm prelabour rupture of membranes, breech presentation and increased rate of caesarean delivery ${ }^{2}{ }^{3}$. However, normal reproductive performance has been seen in association with $\mathrm{them}^{4}$. Communicating uteri are a distinct class of uterine malformations characterized by the presence of a communicating tract between two otherwise separate utero cervical cavities. This malformation was first identified by Musset in 1967. Then musset et all and leo toaff proposed a comprehensive classification of communicating uteri. Ten different groups of communicating uteri has been classified. Five of them are variant or subgroups.

This morphological classification is based on the constant presence of isthmenian communication on the degree of separation of mullerian duct and their partial atresia. These malformations are of the accidental finding clinically because they do not affect patients clinical condition. Therefore the American fertility society does not group them with other female genital tract anomalies.

\section{Case report}

A $21 \mathrm{yr}$ old $2^{\text {nd }}$ gravida, presented to the OBG dept of Dr. Pinnamaneni Siddhartha institute of medical sciences and research foundation with 2 months amennorhoea. She had a first trimester abortion in first pregnancy. She had no complaints, but an early ultra sound ${ }^{6}$ done at 7 Wks of gestational age detected a bicornuate uterus with pregnancy in the right horn. Per speculum examination showed 2 cervix.

A prophylactic cervical stitch was put at 14 wks of gestation. She had regular antenatal visits which are uneventful till 8month.. At 32 wks of gestation she was admitted with complain of pain abdomen. Tocolysis given and patient steroided for lung maturity. USG done revealed decreased liquor and asymmetrical IUGR of the foetus. Doppler showed early fetoplacental insufficiency. Patient treated with amino infusions. Antepartum foetal monitoring done with modified BPP and Doppler. Tocolysis stopped 48hrs after giving corticosteroids.

At 34Wks of gestation the patient presented with prelabour premature rupture of membranes. The stitch was removed. In view of non-reassuring foetal heart rate, an emergency lower segment caeserian section was done with the following intra operative findings: A bicornuate uterus with pregnancy in the right horn seen. The left horn is enlarged to around $14 \mathrm{Wks}$ size and tubes on either cornu are healthy. A live male child in right occipito posterior position weighing $1.7 \mathrm{~kg}$ was delivered. Placenta is located anteriorly in the upper segment. By exteriorizing the uterus, findings are confirmed and communication between the two cavities is noted. She had uneventful post operative period and was discharged on $8^{\text {th }}$ post operative day. 


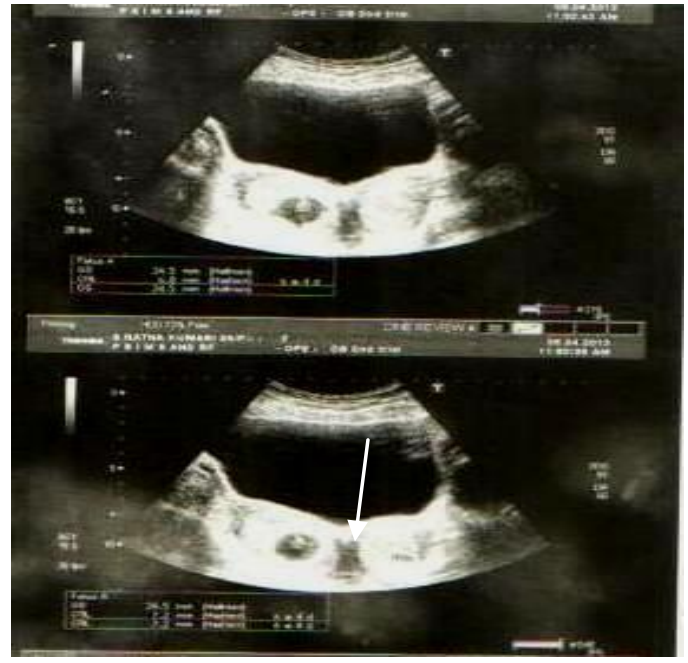

Fig 1: Ultrasound at 7 wks gestation showing fetal echo in the right horn. Septum shown by the white arrow.

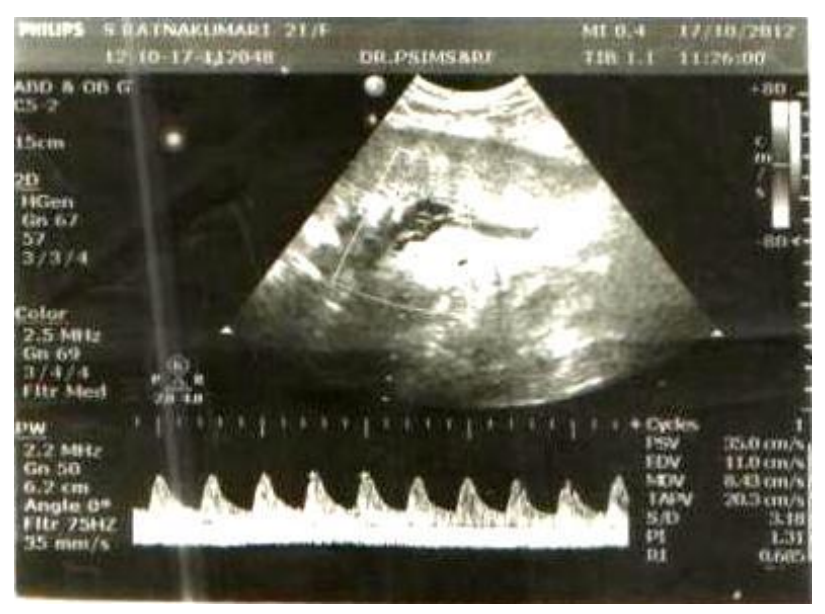

Fig 2: Doppler study showing early feto placental insufficiency.

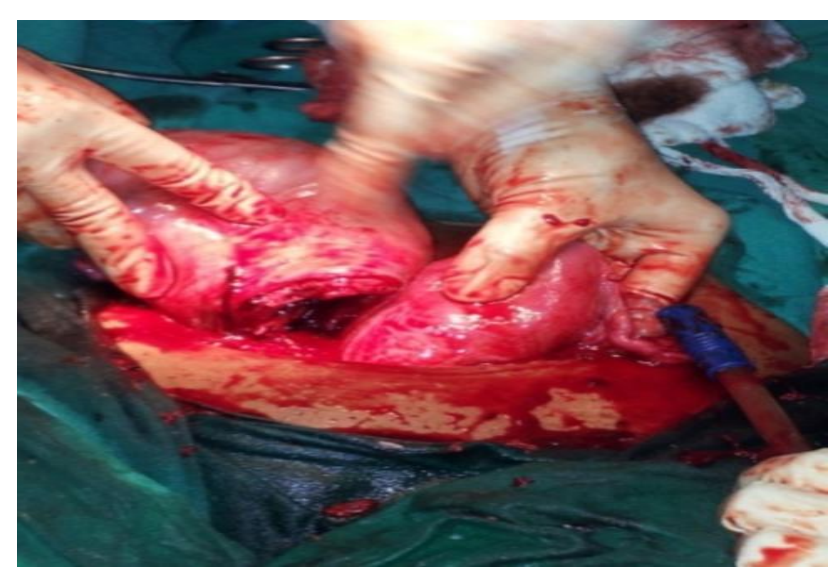

Fig 3: Bicornuate uterus with communicating cavities. 


\section{Discussion}

The incidence of congenital uterine malformation is estimated to be $3-5 \%$ in general population. Bicornuate uterus is a congenital uterine anomaly that results from defective lateral fusion of the paramesonephric ducts at about the tenth week of intrauterine life around the fundus. communicating uteri account for $1-2 \%$ of malformation. Communicating uteri are often an occasional findings during HSG usually performed for infertility or suspected malformation.

The occurrence of a pregnancy in bicornis bicollis uterus has been reported only sporadically in the literature. The detection of congenital uterine anomalies will increase because of heightened physician awareness and improved diagnostic modalities ${ }^{6}$.

In this case the presence of two separate uterine cavities with communication between two at supracervical region is seen. Congenital uterovaginal anomalies can have adverse effects on pregnancy outcome. Offspring of mothers with bicornuate uterus had a four times higher risk of congenital defects than infants born to women with normal uteri ${ }^{5}$.

\section{Conclusion}

Early diagnosis and proper antenatal care is required to successfully manage a pregnancy with bicornuate uterus. Patient with mullerian duct anamolies are known to have a higher incidence of infertility, repeated first, second trimester spontaneous abortions intrauterine growth retardation, fetal malpositions, preterm labor, prelabour preterm rupture of membranes \& retained placenta. Reduced liquor may increase the difficulties while delivering the baby at cesarean section. Anticipation and preparedness to deal with these known complications will ensure positive outcome for the mother and baby.

Staff members, Dept of OBG, Dr. PSIMS \& RF.

\section{Acknowledgement}

Dept. of Radiology, Dr. PSIMS \& RF

\section{References}

[1]. Ernst S: Uterus bicornis bicollis, vagina duplex unilateralis atretica, haematokolpos dexter, aplasia renis dextri (case contribution) Zentralbl Gynakol.1961; 83 :1726-30.

[2]. Martínez-Frías ML, Bermejo Sánchez E, Rodríguez- Pinilla E, Martínez Santana S, Paisán Grisolía L, Egüés Jimeno J, Arroyo Carrera I, Blanco García M, López Soler JA, Martín Bermejo M, Gairi Tahull JM, Moral García A, Galán Gómez E, Frías JL. 1998: Epidemiological aspects of children of women with bicornuate uterus. An Esp Pediatr. 1998; 48 (2): $159-62$.

[3]. Hua M, Odibo A, Longman R,et al. Congenital uterine anomalies and adverse pregnancy outcome. American Journal of Obstetrics and Gynaecology, 2011; 204(1): 334-335.

[4]. Simon C, Martinex I, Pardo F, Tartajada M, Iellicor A. Mullerian defects in women with normal reproductive outcome. Fertil Steril1991; 561192-3.

[5]. María Luisa, Martínez-Frías*, Eva Bermejo, Elvira Rodríguez-Pinilla, and Jaime Luis Frías. 1998: Congenital Anomalies in the Offspring of Mothers With a Bicornuate Uterus. Pediatr 2002; 101 (4): p10

[6]. Salim R, Jurkoric D. Assessing congential uterine anomalies: the role of three dimensioned ultrasonography. Best Pract Res Clin Obstet Gynaecol, 2004; 1829-36 